\title{
A CF-1988 na Berlinda: trinta anos de disputas por um projeto nacional de desenvolvimento nos trópicos
}

\author{
The CF-1988 in the spotlight: thirty years of disputes over a national \\ development project in the tropics
}

José Celso Pereira Cardoso Junior $\mathbf{1}^{\mathbf{2}}$

DOI: $10.1590 / 0103-110420185302$

\section{Apresentação}

Este artigo atende a chamamento de forças progressistas ainda presentes na sociedade brasileira, dentro e fora dos aparelhos de Estado em seus diversos níveis de organização e atuação, com vistas a mais um repensar sobre o Brasil. Em particular, trataremos do papel institucional desempenhado pelas políticas sociais estruturadas a partir da Constituição Federal de 1988 (CF-1988), com vistas a um projeto nacional de desenvolvimento.

Assim, para além desta breve apresentação, o artigo oferece, na seção 1, uma visão panorâmica acerca dos três grandes momentos situacionais pelos quais acreditamos ter passado a CF-1988 neste interregno de 30 anos, a saber: i) entre 1988 e 2002: contestação e acomodação; ii) entre 2003 e 2014: acomodação e conciliação; e iii) entre 2016 e 2018: destituição e desconstrução.

Posteriormente, na seção 2, realizamos uma incursão mais amiúde sobre a dimensão social instituída a partir da CF-1988, enfatizando tanto o caráter híbrido e insuficiente do arranjo constitucional original como o processo contraditório de implementação, avanços e recuos desde então. Na seção 3, por sua vez, destacamos o caráter regressivo, excludente e insustentável do novo (porém pior!) arranjo fiscal-social em implementação desde 2016, apontando, já nas considerações finais, para os riscos sociais e para o retrocesso civilizatório presente na perspectiva de continuidade desse modelo ao País e a sua população.

1 Instituto de Pesquisa Econômica Aplicada (Ipea)

- Brasília (DF), Brasil. Orcid: https://orcid. org/0000-0002-84636844

zcelsojr@gmail.com

\section{CF 30 anos: ciclos de contestação, acomodação e desconstrução constitucional}

Como se sabe, em outubro de 2018, a CF-1988 completará 30 anos desde sua promulgação. Até o momento, esta é (ou terá sido) a Constituição Federal mais longeva da história republicana brasileira, a viger sob regras democráticas por ela mesma estabelecidas - e obedecidas! -, ao menos até 2016.

Em termos bibliográficos, vários trabalhos relevantes sobre a CF-1988 foram produzidos por ocasião dos seus 20 anos de vigência' ${ }^{1-13}$. Muitos mais, aliás, que os que haviam sido 
produzidos por ocasião dos 10 anos e, provavelmente, muitos mais do que parece serão produzidos agora por ocasião dos seus 30 anos. Apenas esse fato já dá mostras de quão diferentes (pessimista, otimista e novamente pessimista) vêm sendo as efemérides decenais de sua existência no País; e isso demonstra a importância desse esforço no sentido de capturar e caracterizar o 'momento constitucional' atual.

Para além de seu tempo formal de vigência, a CF-1988 é importante porque sob suas regras gerais o País instituiu e tentou implementar (não sem resistências de toda ordem, várias delas infelizmente exitosas) um amplo conjunto de direitos civis, políticos, sociais e econômicos. Grande parte da (ainda que pífia) melhoria distributiva havida, por exemplo, entre 1995 e 2015, deveu-se aos esforços de implementação de dispositivos constitucionais atrelados às políticas sociais em suas diversas áreas de atuação, tais como: previdência e assistência social, trabalho e renda, educação e saúde, entre outras. Tal resultado distributivo, é bom que se diga, ocorreu pelo lado do gasto público, e foi contrabalançado por tendências concentradoras advindas tanto da estrutura tributária regressiva como da primazia do gasto financeiro sobre o gasto real, ambos os aspectos, ou presentes na CF-1988 desde o início, ou posteriormente nela sacramentados por meio de Emendas Constitucionais (EC) que pioraram aspectos cruciais já problemáticos do texto constitucional nesses temas ligados à ordem tributária, econômica e financeira.

Por outro lado, a CF-1988 também buscou reorganizar aparatos estatais em diversos campos de atuação, promovendo uma verdadeira reforma administrativa em termos de reestruturação e modos de funcionamento da máquina pública. São exemplos disso os regramentos postos em operação (também aqui de forma diferenciada no tempo e muitas vezes contraditória entre si) nas áreas do direito econômico e financeiro, da arrecadação tributária, da orçamentação e gastos públicos, do planejamento e gestão governamental, da participação social e controles estatais, além dos aspectos formais relativos ao funcionamento e (des)equilíbrio entre poderes (Executivo, Legislativo e Judiciário, com o Ministério Público tendo nascido e se fortalecido desde então) e entre entes federados.

Dadas as suas abrangência e profundidade temáticas, a CF-1988 nunca foi consensual no Brasil, razão pela qual, desde sua promulgação, a sociedade brasileira vem se dividindo entre aqueles que simplesmente querem derrogá-la, visando instaurar uma ordem constitucional majoritariamente liberal-conservadora, e aqueles que desejam ou mantê-la em seus traços fundamentais, ou fazê-la avançar em termos sociais, econômicos, políticos etc., em um sentido de maior controle estatal sobre a economia e maior congraçamento tanto populacional quanto territorial.

A questão de fundo, portanto, é que, desde a promulgação da CF-1988, há no Brasil, grosso modo, dois projetos políticos antagônicos em disputa no debate corrente. De um lado, coloca-se novamente em pauta - por setores conservadores da sociedade, comunidades da política (partidos, sindicatos e outras agremiações) e da própria burocracia, além da mídia e empresariado - o caminho liberal, de orientação privatista e individualista, que havia vivenciado melhores dias na década de 1990, mas que, desde 2016, vem conseguindo impor uma agenda 'abrangente, profunda e veloz' de retrocessos institucionais em áreas críticas da regulação econômica, social e política brasileira.

De outro lado, embora raramente tenha tido força política suficiente no cenário nacional, permanece como possibilidade - defendida por setores do campo progressista, dentro e fora das estruturas de governo - a via da expansão ou universalização integral dos direitos civis, políticos e sociais, tais quais os promulgados pela CF-1988. Todavia, é preciso ter claro que as bases materiais e as condições políticas hoje vigentes para a efetivação de tais direitos estão ainda muito distantes das mínimas necessárias à sua consecução. 
Não por outra razão, talvez seja possível estabelecer ao menos três momentos por meio dos quais o embate acima vem se desenrolando no País desde o início. Resumidamente, entre ' 1988 e 2002', teria vigorado um momento de 'contestação e acomodação' do pacto constitucional original. Depois de o governo Sarney ter-se colocado publicamente contra a CF-1988 recém-promulgada, o conturbado governo Collor de Mello buscou contestá-la abertamente, sem, contudo, ter tido êxito em suas tentativas de reformas. Após seu impeachment em 1992, o Brasil vivenciou, sob o governo provisório de Itamar Franco, um período de acomodação geral, pois, a despeito da revisão constitucional havida em 1993, o que estava em jogo era a transição política para as próximas eleições, que haveria de ser em 1994. Durante os dois mandatos de Fernando Henrique Cardoso (FHC) (1995 a 2002), houve novamente um período forte de contestação e reformas constitucionais de grande monta, sobretudo entre 1995 e 1998. O ímpeto destas se arrefeceu ao longo do seu segundo mandato (1999 a 2002), tanto em função das crises econômica e social em curso como também por causa da aglutinação de forças políticas de oposição ao governo, que conseguiram barrar ou adiar votações importantes ao projeto liberal de reformas constitucionais. Dessa forma, apesar das 45 EC aprovadas em seus primeiros 14 anos de vigência democrática, a maioria das quais com caráter claramente contrário ao espírito original das leis, pode-se dizer que houve também certa acomodação de princípios e diretrizes constitucionais relevantes aos pactos sociais e políticos de então.

Tabela 1: Total de Emendas por mandato presidencial. Brasil.

\begin{tabular}{|c|c|c|c|}
\hline Momentos & Mandatos Presidenciais & № das Emendas & Total 1988-2018 \\
\hline \multirow[t]{5}{*}{ Momento 1: Contestação e Acomodação } & 1988 - 1989: José Sarney & & 0 \\
\hline & 1990 - 1992: F.Collor de Mello & EC $1-E C 2$ & 2 \\
\hline & 1993 - 1994: Itamar Franco & 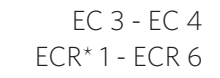 & 8 \\
\hline & 1995 - 1998: FHC-1 & EC 5 - EC 20 & 16 \\
\hline & 1999 - 2002: FHC-2 & EC $21-$ EC 39 & 19 \\
\hline Total de Emendas Momento 1 & & & 45 \\
\hline \multirow[t]{3}{*}{ Momento 2: Acomodação e Conciliação } & 2003 - 2006: Lula-1 & EC $40-$ EC 53 & 14 \\
\hline & 2007 - 2010: Lula-2 & EC $54-$ EC 67 & 14 \\
\hline & 2011 - 2014: Dilma-1 & EC $68-$ EC 84 & 17 \\
\hline Total de Emendas Momento 2 & & & 45 \\
\hline \multirow[t]{2}{*}{ Momento 2: Destituição e Desconstrução } & 2015 - 2016: Dilma-2 & EC 85 - EC 95 & 11 \\
\hline & 2016 - 2018: Temer & EC 96 - EC 99 & 4 \\
\hline Total de Emendas Momento 3 & & & 15 \\
\hline Total 1988-2018 & & & 105 \\
\hline
\end{tabular}

Fontes: Elaboração própria baseada na Constituição Federal de 1988.

*ECR - Emendas Constitucionais de Revisão. 
Por sua vez, entre 2003 e 2014, teria havido um momento que poderíamos chamar de 'acomodação e conciliação' relativamente à CF-1988 e propostas de reformas. Durante os dois mandatos presidenciais de Lula da Silva (2003 a 2010, mas sobretudo no segundo) e ainda durante o primeiro mandato de Dilma Rousseff (2011 a 2014), a despeito de 45 EC aprovadas, quase todas elas fruto de embates políticos e ideológicos de monta, de modo que nem todas possuíram sentido contrário ao espírito original das leis, houve também esforços institucionais no sentido de acomodar e implementar dispositivos constitucionais importantes, bem como conciliar a discussão de temas controversos e mesmo postergar a aprovação de medidas contrárias ao ideário menos liberal dos governos de então.

Por fim, entre ' 2015 e 2018', já em um contexto de crises econômica e política abertas, cujo desfecho institucional foi - por ora - a destituição de Dilma Rousseff e a tomada de poder pelo consórcio liberal-conservador formado por toda a oposição parlamentar de então, e também por parte expressiva da coalizão de apoio (de centro e de direita) reeleita em 2014, conforma-se um momento que se vai caracterizando como sendo de 'destituição e desconstrução' abrangente, profunda e veloz dos fundamentos basilares da CF-1988. Todavia isso apenas se faz possível em função das situações (formais e informais) de 'excepcionalidade de medidas e criminalização de direitos e atores sociais' que se vem anunciando e produzindo principalmente desde 2015 (com o aguçamento da ingovernabilidade já durante o primeiro ano do segundo mandato de Dilma) e, com maior ênfase, desde o golpe em 2016, a partir de quando os blocos conservadores no comando dos três poderes da República, com o Ministério Público, os Tribunais de Contas, a Polícia Federal, a grande mídia corporativa e o grande empresariado nacional e internacional, financeiro e financeirizado, valendo-se da anomia, alienação, desinformação, cooptação, desalento e/ou resignação social em curso, vem conseguindo pautar e sancionar (até o momento, julho de 2018) 15 EC e outras tantas reformas infraconstitucionais abertamente contrárias ao pacto social e político forjado - e em 'lenta, gradual e insegura acomodação' - desde a CF-1988.

Em suma, dada a quantidade total de EC já aprovadas e seu perfil majoritariamente contrário ao espírito original da CF-1988, é possível afirmar que, 30 anos depois, o 'Brasil possui hoje, na prática, uma Constituição Federal Desfigurada, sem, no entanto, ter vivenciado, para tanto, uma outra Assembleia Constituinte'. Vale dizer: mudanças feitas sem consulta, participação nem deliberação da vontade e soberania popular.

Pelo exposto, e sem desconsiderar a distância que há - a todo o momento e lugar - entre os fatos e as leis, ou seja, sem jamais acreditar que a mera existência formal da CF-1988 possa ser posta em movimento tal e qual a letra das leis, portanto, cientes de que qualquer aparato legal nada mais é do que o resultado (mais ou menos transitório ou permanente) dos embates políticos, econômicos, sociais, culturais etc. de uma dada sociedade em determinado tempo e contexto histórico, vê-se que tais aparatos, por sua vez, trazem em si determinados princípios, diretrizes e projetos políticos cuja implementação (isto é, sua conversão em fatos da realidade) depende evidentemente da disputa social e política - idealmente arbitrada por regras supostamente republicanas presentes no sistema democrático vigente - que se coloca em movimento desde a sua promulgação.

Isso significa que a discussão sobre a CF-1988 não está descolada da vida cotidiana das pessoas e instituições (sejam essas públicas-estatais, não estatais, e privadas), as quais são criadas, transformadas e mobilizadas para a aplicação ou contestação de cada um dos tais normativos legais. Significa, por isso mesmo, que não é assunto menor ou sem consequências uma discussão que pretenda não apenas proceder a um balanço crítico (ainda que não exaustivo) da experiência 
constitucional brasileira ao longo desses 30 anos de existência (1988-2018), perscrutando o teor ou sentido das mudanças havidas nas diversas fases de contestação, acomodação, conciliação e desconstrução efetiva ora em curso, como também oferecer uma visão prospectiva e propositiva, perfilada ao projeto de construção e desenvolvimento da nação, que lhe é evidente.

Nesse sentido, cabe, na sequência, a tarefa de acompanhar mais amiúde o tema das políticas sociais tais quais emanaram da ordem social da CF-1988 e vieram sendo concretamente implementadas em meio às disputas políticas e projetos de país mais evidentes desde então.

\section{CF 30 anos: da constituição cidadã à cidadania restrita}

Como amplamente reconhecido, a CF-1988 é um marco na história das políticas sociais brasileiras. Em seu capítulo dedicado aos direitos sociais, ela promove mudança formal sem precedentes na trajetória de construção da intervenção do Estado no campo social. Trata-se de alteração qualitativa muito importante em termos da concepção de proteção que havia vigorado no País até então, pois inseriu os princípios da 'seguridade social' e da 'universalização' em áreas vitais da reprodução social.

No caso brasileiro, ambas as influências estiveram presentes nos processos nacionais de redemocratização e reconstitucionalização dos anos 1980, e não foi à toa que os princípios da 'seguridade social' e da 'universalização' acabaram - felizmente - se inscrevendo na CF-1988, apesar do contexto histórico mundial já fortemente adverso à época, matizado pela nova fase de hegemonia liberal que se propagava desde os EUA de Ronald Reagan e da Inglaterra de Margareth Thatcher.

A Constituição Federal brasileira de 1988, não obstante, rompeu com a necessidade do vínculo empregatício-contributivo na estruturação e concessão de benefícios previdenciários aos trabalhadores oriundos do mundo rural. Em segundo lugar, transformou o conjunto de ações assistencialistas do passado em embrião para a construção de uma política de assistência social amplamente inclusiva, ao prever a Lei Orgânica da Assistência Social (Loas) e o arco de programas governamentais que lhe dão sustentação. Em terceiro, estabeleceu o marco institucional inicial para a construção de uma estratégia de universalização das políticas de educação e saúde.

Nos três casos, há mudança qualitativa quanto ao status das políticas sociais relativamente a suas respectivas condições pretéritas de funcionamento. Além disso, ao propor novas e mais amplas fontes de financiamento, alteração esta consagrada na criação do Orçamento da Seguridade Social, estabeleceu condições materiais objetivas para efetivação e preservação dos novos direitos de cidadania inscritos na ideia de seguridade e na prática da universalização.

No entanto, apesar desse conjunto de avanços legais, uma combinação de fatores (econômico-estruturais e político-conjunturais) fez com que uma nova estratégia social fosse sendo gestada e implementada ao longo da década de 1990, em grande medida na contracorrente das inovações sociais constitucionalizadas em 1988. Essa nova estratégia social se caracterizaria por combinar cinco diretrizes gerais no campo da proteção social: 'universalização restrita, privatização crescente, descentralização fiscal, focalização sobre a pobreza e aumento da participação social compensatória'. Trata-se de reforma social de orientação liberalizante, em termos da concepção, implementação e gestão das políticas sociais em várias áreas do mundo do bem-estar (trabalho, previdência e assistência social, saúde, educação, habitação, segurança pública etc.).

Muito embora a CF-1988 tenha deixado em aberto a participação dos setores privados (lucrativos e não lucrativos) na complementação da provisão estatal de proteção social, 
parece-nos bastante evidente que a estratégia social levada a cabo ao longo das últimas três décadas, vista retrospectivamente como a resultante do embate de forças políticas e ideológicas presentes tanto na disputa entre os setores público e privado como intrassetores públicos, exacerbou esta característica pró-mercado das políticas sociais, em detrimento do princípio público e universalizante que, na verdade, está na base do capítulo constitucional relativo à ordem social.

Não por outra razão, cunhamos aqui a expressão 'universalização restrita' para nos referir ao fato de que a universalidade da cobertura e do atendimento, quanto ao conjunto de políticas de seguridade (saúde, previdência e assistência social) e educação, não se firmou nem como princípio ideológico geral nem como prática do Estado na implementação concreta de tais políticas, passados já 30 anos (1988-2018) da promulgação da Carta Constitucional.

Porquanto a provisão de saúde e a educação fundamental tenham alcançado níveis bastante elevados de cobertura e, mais importante, consolidado, ao menos formalmente, o caráter universalizante (público e gratuito) dos programas e ações governamentais por todo o território nacional, isso não impediu o avanço e a concorrência (muito mais que a cooperação/complementação) dos setores privados, tanto na saúde, pela oferta limitada e pela qualidade questionável dos serviços públicos, como na educação, em virtude da ênfase conferida pelo Estado ao ensino fundamental, tendo o mercado privado de escolas de ensino médio e faculdades e universidades particulares crescido fortemente desde 1988.

Por sua vez, as áreas de previdência e assistência social também tiveram a universalidade da cobertura e do atendimento limitada ao longo dos anos 1990. No caso da previdência, com exceção do grande aumento de cobertura obtido pela implementação da previdência rural, cujo avanço social reside no fato de que não guarda vínculo contributivo direto com os benefícios concedidos, o Regime Geral de Previdência Social - Urbano (RGPSurbano) teve, na verdade, poder bastante limitado para ampliar sua cobertura na década liberal. Isso se deveu, fundamentalmente, à exigência de contribuição prévia à concessão de benefícios, fulcro por excelência do modelo europeu-continental (ou meritocrático-contributivo), em contexto de alargamento da informalização e precarização das relações de trabalho no País. Como a estrutura de remunerações vinculadas ao RGPS-urbano é historicamente baixa no Brasil, o nível dos benefícios acaba por refletir e sancionar a péssima distribuição de renda produzida pelo setor privado, abrindo espaço, dessa forma, para o surgimento de um setor de previdência complementar com potencial para capturar as franjas média e superior da distribuição de rendimentos.

No caso da assistência social, embora se constitua em área de atendimento exclusivamente voltada para camadas pobres e desassistidas da população, possui também poder limitado de ampliação da cobertura, devido, basicamente, aos estreitos limites estabelecidos pelos critérios de renda domiciliar 'per capita' que são utilizados como condição de elegibilidade aos benefícios. Em um país no qual um contingente muito grande da população percebe rendimentos muito baixos, tais que os colocariam, em outras condições de civilidade, abaixo de linhas de pobreza não tão reduzidas, critérios restritivos para a concessão de benefícios assistenciais acabam sendo a forma encontrada pelo Estado para regular o gasto social nessa área e, portanto, impedir pressões indesejadas sobre a estrutura geral de financiamento público.

Pelo exposto, pelo menos duas questões devem ser ressaltadas.

A primeira delas é que o esforço de financiamento para uma estratégia social amplamente universalizante, no caso brasileiro, teria de ser superior ao esforço de fato realizado pelo Estado ao longo dessas três 
décadas, motivo pelo qual o País tão somente conseguiu implantar um tipo de universalização restrita das suas principais políticas sociais.

A segunda é que o grande impulso dado à 'privatização' - ou aumento de participação dos setores privados (lucrativos ou não) na provisão total de bens e serviços sociais à população - em áreas-chave, como saúde, educação e previdência, pode ser visto como parte da estratégia social guiada pelo próprio Estado, na medida em que é ele quem define o marco regulatório de atuação dos entes privados em cada setor da economia, impondo, com isso, a direção, o ritmo e a intensidade da acumulação de capital em cada caso concreto.

Outras três estratégias coerentes e complementares às anteriores também foram se fortalecendo desde a década de 1990. Em primeiro lugar, a descentralização de parte das atribuições fiscais da União para Estados e municípios. Em segundo, a focalização das políticas, programas e ações governamentais sobre parcela considerada mais pobre da população. Finalmente, o aumento da participação social organizada - setor público não estatal, ou setor privado não lucrativo - em atividades de cunho social.

A 'descentralização' nasceu na esteira da redemocratização no início dos anos 1980 e se consolidou como um dos princípios fundamentais na discussão constituinte acerca do novo formato institucional que as políticas sociais deveriam ter. Princípio originalmente ligado à ideia de maior envolvimento e participação dos entes subnacionais e também da sociedade civil na formulação, implementação, gestão, controle e avaliação das políticas sociais, a descentralização acabou se traduzindo em parte da estratégia social do governo federal para transferir responsabilidades e gastos sociais a Estados e municípios. Ainda que a ideia da descentralização como princípio fundamental de gestão pública tenha se mantido no discurso oficial, reinou de fato grande descompromisso dos entes federados com aspectos da descentralização que não estivessem diretamente ligados à eficiência das políticas e, sobretudo, dos gastos sociais. Por isso, falamos apenas em descentralização fiscal das políticas sociais, já que, na prática, ela não se revestiu, senão em raras exceções até o momento, dos princípios de envolvimento populacional efetivo e participação social na gestão da coisa pública.

Por sua vez, a 'focalização' das políticas (leia-se: dos recursos) sociais visando ao combate direto à pobreza nasceu e se consolidou como princípio ideológico que se construiu e se implementou, desde os anos 1990, na contramão dos preceitos universalizantes impressos na CF-1988. É muito importante atentar para o fato de que, ao deslocar o foco da discussão do desenvolvimento com inserção pelo trabalho produtivo e socialmente útil para o tema do combate à pobreza via, supostamente, uma mais eficiente aplicação dos recursos sociais, a focalização na verdade se complementa coerentemente com o conjunto da estratégia social montada nos anos 1990 e ainda vigente neste novo milênio.

Por fim, aliado à focalização da problemática social sobre a pobreza, também se observa a construção de certo nível de comprometimento de setores públicos não estatais - ou setores privados não lucrativos - em relação à execução de ações sociais voluntárias ou compartilhadas com o próprio setor público estatal. O aumento da 'participação social' organizada - porém compensatória - na composição de certa estratégia geral de atendimento social ao longo das décadas de 1990 e 2000 esteve originalmente ligado à ideia de maior envolvimento e participação da sociedade civil na formulação, implementação, gestão, controle e avaliação das políticas sociais. Contudo, o sentido desta atuação, bem como os resultados até o momento alcançados, em termos de efetividade das instituições participativas, é ainda bastante ambíguo para ser avaliado adequadamente neste momento. 


\section{CF 30 anos: ruptura democrática e retrocesso civilizatório}

Em termos gerais, é possível dizer que a estratégia social dos governos que administraram as políticas públicas brasileiras desde a CF-1988 era também uma estratégia para resolver o problema do financiamento das políticas sociais, ainda que fosse uma estratégia tão somente implícita, jamais declarada. 'Universalização restrita, focalização sobre a pobreza, descentralização fiscal, participação social e privatização' da parte rentável das políticas sociais concorrem, conjunta e estruturalmente, para limitar as necessidades de financiamento do gasto público social, notadamente em âmbito federal, o que é também coerente e necessário à estratégia mais geral de contenção fiscal do governo em face dos constrangimentos macroeconômicos (auto) impostos pela primazia da estabilização monetária sobre qualquer outra alternativa de política econômica.

Não obstante, é importante mencionar que a estrutura de financiamento da área social no Brasil foi alterada, a partir da CF-1988, rumo a promover incremento de recursos apoiado na diversificação de bases tributárias. Isso, aliado a vinculações sociais específicas, estabeleceria melhores condições materiais para a efetivação e preservação dos direitos inscritos na ideia de seguridade e na prática da universalização. Importa ressaltar a existência de grande diversidade nos esquemas de financiamento das diversas políticas sociais, diversidade esta que congrega as seguintes fontes: recursos orçamentários provenientes de impostos, contribuições sociais, contribuiç̧̃es econômicas e outras de menor importância.

Conquanto essa diversidade de fontes possa ser característica institucional positiva em contexto nacional marcado por grande heterogeneidade social, a exigir soluções diferenciadas para problemas de natureza diversa, acaba, no caso brasileiro, contribuindo para a sensação de que tentativas de racionalização e definição de princípios tributários mais justos para o financiamento social estariam fadadas ao fracasso, seja pela complexidade em si de tal empreitada, seja pelo conjunto de interesses divergentes envolvidos.

Embora saibamos que os marcos gerais dessa institucionalidade tributária derivem de circunstâncias e fatores de ordem econômica e de interesses e disputas políticas importantes em cada arena decisória, não deixa de ser sintomático verificar que:

- 'Primeiro', os princípios que deveriam estruturar os esquemas de financiamento das políticas sociais no País, embora em grande parte consagrados na legislação, não têm sido, por inteiro, aplicados na orçamentação da Seguridade Social;

- 'Segundo', que isso acaba contrapondo, na luta cotidiana por recursos, interesses e setores inteiros das áreas sociais, os quais, de outra maneira, poderiam convergir, tendo em vista princípios comuns de justiça distributiva;

- 'Terceiro', por fim, que o arranjo tributário em cada caso concreto das políticas sociais mascara (mas não esconde!) diversos graus de injustiça (e, portanto, ineficácia) distributiva, tal qual exemplificamos rapidamente abaixo, tendo como referência apenas alguns casos paradigmáticos:

- Ensino Fundamental: embora redistributivo no gasto, sobretudo, o é por atender aos setores populacionais mais mal posicionados na estrutura social desigual do País. Os programas da área, embora financiados com recursos gerais do orçamento público, incorrem em certa dose de injustiça distributiva pelo simples fato de que é a própria estrutura tributária brasileira regressiva quanto ao financiamento em geral;

- Saúde: o gasto é distributivo, sobretudo, por atender aos segmentos mais pobres da estrutura social brasileira, sendo o 
financiamento parcialmente injusto por depender, em grande parte, de contribuições que, embora incidentes sobre bases variadas, são onerosas para os setores produtivos da economia e regressivas em seus próprios termos;

- RGPS-urbano: embora parcialmente justo no esquema de financiamento, certamente é não redistributivo do ponto de vista do gasto, pois tal modelo tende sempre a sancionar a estrutura de distribuição existente;

- RGPS-rural: conquanto seja bastante redistributivo no gasto, é relativamente injusto no financiamento, posto que se vale das contribuições de empregadores e trabalhadores urbanos para financiar-se;

- Seguro-desemprego: carrega certa dose de injustiça distributiva na medida em que se destina exclusivamente a trabalhadores desempregados do setor formal da economia. No entanto, este é um programa financiado basicamente com recursos do Fundo de Amparo ao Trabalhador - FAT (PIS/ Pasep - Programa de Integração Social e Programa de Formação do Patrimônio do Servidor Público), fundo patrimonial recolhido sobre o faturamento de empresas que não necessariamente têm, em seu corpo funcional, apenas trabalhadores formalizados.

Tais aspectos - é importante dizer - não apenas não serão resolvidos pela EC 95/2017 como, provavelmente, serão severamente agravados durante a vigência, por 20 exercícios financeiros seguidos, do chamado novo (porém pior!) regime fiscal brasileiro. A EC 95/2017 fixa, em cada ano, um limite individualizado para a despesa primária total do Executivo e demais poderes da esfera federal. Para fins de verificação do cumprimento do limite estabelecido a cada ano, será considerado o somatório das despesas que afetam o resultado primário no exercício, incluídos os restos a pagar referentes às despesas primárias. No caso de descumprimento do limite estabelecido, o Poder Executivo deverá ajustar-se, já no exercício subsequente, por meio do congelamento de subsídios e vedando a ampliação de desonerações tributárias que provoquem renúncia de receita. Por fim, a EC 95/2017 afirma que as vedações introduzidas pelo novo regime fiscal não constituirão obrigação de pagamento futuro pela União ou direitos de outrem sobre o erário.

Pelo exposto, concluímos que estudos que procuram avaliar o impacto distributivo das políticas sociais somente pelo lado dos gastos não são capazes de gerar resultados metodologicamente satisfatórios. Dada a complexidade das relações que existem entre, por um lado, a estrutura de financiamento social e, por outro, o padrão fiscal-financeiro dos gastos públicos, não é possível avaliar adequadamente os impactos sociais dos gastos sem considerar também, como dimensão crucial dos problemas de efetividade e eficácia distributivas, o lado do financiamento das políticas e programas governamentais da área social.

Essa afirmação, compartilhada por Associação Nacional dos Auditores Fiscais da Receita Federal do Brasil (Anfip) e Federação Nacional do Fisco Estadual e Distrital (Fenafisco) (2018), leva-nos a sugerir que parte dos problemas de eficácia distributiva de algumas importantes políticas sociais de nível federal no Brasil resida nos arranjos tributários que sustentam o financiamento social. Por um lado, a tributação sobre o consumo de bens e serviços incide mais que proporcionalmente sobre as camadas de menores rendimentos da população; por outro, ela é historicamente a base de incidência mais importante para a composição da carga tributária nacional. Adicionalmente, é preciso mencionar a baixa utilização que se faz da propriedade como base de composição da carga tributária nacional. Nunca mais que $1,5 \%$ do Produto Interno Bruto (PIB) é arrecadado anualmente 
no Brasil em nome das diversas formas de propriedade existentes, a despeito do caráter potencialmente progressivo desta base de incidência.

Não obstante, vários autores conservadores argumentam que o potencial de arrecadação de tributos sobre a renda é reduzido no Brasil porque o nível de rendimentos gerais é muito baixo e a base de incidência do Imposto sobre a Renda da Pessoa Física (IRPF) é muito estreita. Por este motivo, acreditam que reformas tributárias, no contexto brasileiro, deveriam se preocupar, quase que exclusivamente, com aspectos ligados à racionalização dos impostos sobre o consumo, ainda que isso não seja suficiente para reverter a regressividade dessa forma de tributação. Assim, defendem que se procure resolver o problema da desigualdade de rendimentos da sociedade brasileira mediante utilização de créditos fiscais e transferências monetárias aos segmentos ocupados de baixa renda e àqueles cobertos pelos programas focalizados de combate à pobreza.

Ora, tanto o diagnóstico acima exposto quanto a proposta de solução parecem não levar adequadamente em consideração os seguintes aspectos:

- O quadro de extrema desigualdade e heterogeneidade que marca a estrutura de rendimentos das pessoas ocupadas no Brasil;

- Os princípios de justiça distributiva e progressividade contidos nos impostos sobre a renda de pessoas físicas e de empresas;

- O potencial não utilizado de arrecadação sobre a renda e sobre o patrimônio das classes média-alta e alta da sociedade brasileira;

- A regressividade intrínseca de qualquer base tributária centrada sobre o consumo de bens e serviços, especialmente aquela proveniente da grande desigualdade e heterogeneidade presentes na estrutura de consumo da sociedade brasileira;
- O fato de que transferências monetárias de caráter assistencialista, ao visarem tão somente atenuar os resultados sociais do processo distributivo, ainda que possam servir como estratégia direta de combate à pobreza, não constituem solução estrutural para o problema da desigualdade de renda do País.

Em resumo, queremos chamar atenção para o fato de que qualquer estratégia de ampliação das políticas (e, portanto, dos gastos) sociais só pode ter efeito redistributivo mais potente se colado a uma estrutura tributária (lado da arrecadação) condizente com princípios conhecidos de justiça distributiva. No caso concreto que estamos analisando, isso equivale a pensar uma estrutura tributária centrada sobre o patrimônio (ou seja, estoque de riqueza real e financeira, tanto de pessoas físicas como jurídicas, cuja estrutura de distribuição no Brasil é vexatória) e progressiva no que tange aos fluxos de renda.

\section{Considerações finais: $o$ golpe de 2016 e o futuro da proteção social no Brasil}

Desde a CF-1988, setores rentáveis das políticas sociais (notadamente: previdência, saúde, educação, cultura, esportes, trabalho e segurança pública) convivem com constrangimentos tecnopolíticos à universalização de fato de seus principais programas, e paulatinamente se observa o crescimento normativo, regulatório e ideológico da provisão dessas políticas sob a égide privada. Por sua vez, as chamadas políticas sociais de nova geração (direitos humanos e de cidadania para públicos e situações específicas), depois de uma fase de institucionalização promissora até 2014, encontram-se material e ideologicamente inibidas, sobretudo desde o golpe de 2016, com a reorientação regressiva, excludente e insustentável das políticas públicas dele decorrente. 
No campo especificamente social, os governos brasileiros dos anos 1990 já haviam conduzido várias mudanças no sistema nacional de proteção social, com a justificativa de que o modelo de proteção inscrito na Constituição seria muito custoso para a estrutura fiscal do Estado, além de inadequado em face das propostas de reforma administrativa e do sistema econômico. Por essa razão, o núcleo duro de qualquer sistema de bem-estar - a saber: as condições de regulação do mercado de trabalho e o modelo de previdência social - passaram por importantes mudanças institucionais durante a década de 1990.

No caso do mercado de trabalho, em que praticamente a maior parte da população ativa nunca foi contribuinte do sistema de proteção, a onda de liberalização das regras de regulação laboral levada a cabo nos anos 1990 fez com que a cobertura social no âmbito da previdência pública não aumentasse significativamente. De acordo com essa assertiva, constata-se hoje que a causa para a crise do mundo do trabalho no Brasil não esteve (e não está) ligada à legislação existente, mas basicamente à profunda e persistente crise do Estado e da economia, o que desqualifica as propostas liberais de reforma trabalhista sempre em voga no País.

$\mathrm{Na}$ esfera previdenciária brasileira, a reforma governamental iniciada nos anos 1990 parece também não ter trazido resultados alvissareiros, basicamente por duas razões. Em primeiro lugar, porque em contexto de grande desigualdade de rendimentos, e no qual também os níveis absolutos de remuneração são bastante baixos, somente uma pequena parte da população ocupada pode ter acesso aos sistemas privados de previdência complementar. Em segundo lugar, as mudanças pretendidas para a resolução dos problemas estruturais do sistema de seguridade púbico sempre foram incompatíveis tanto com a heterogeneidade do mercado de trabalho quanto com as propostas recorrentes de desregulamentação trabalhista.
Por tudo o que foi dito acima, o projeto golpista de desenvolvimento, se é que se pode chamar de desenvolvimento o ideário liberal-conservador ora em curso no Brasil, deixa claro que a discussão não é tanto saber se a CF-1988 cabe ou não cabe no orçamento nacional. Muito mais importante a constatar é que a própria sociedade brasileira, em sua heterogeneidade, diversidade, desigualdades, pluralidade e necessidades, enfim, é esta que definitivamente não cabe no projeto golpista.

Em outras palavras, como reduzir a plêiade de manifestações, interesses e necessidades políticas, econômicas, sociais, culturais, raciais, sexuais, etárias, artísticas, religiosas, intelectuais, internacionais etc. de uma nação como a brasileira a um ideário ideológico elitista e excludente? Simplesmente impossível!

Então, a questão não é ajustar e restringir artificialmente toda a grandeza e pujança da sociedade brasileira a leis fiscais e parâmetros orçamentários como se leis e parâmetros fossem imposições da natureza. A questão é justamente buscar os arranjos políticos, sociais, institucionais capazes de melhor compatibilizar capacidades estatais e societais, instrumentos governamentais e de mercado, no sentido da ampliação democrática da nação - ao invés da sua castração. Para tanto, torna-se imprescindível redefinir o papel do mercado e da acumulação capitalista em suas relações com o Estado e com o poder público instituído.

Pelo lado do financiamento social, sabe-se que a estratégia governamental de ampliar e recentralizar a carga tributária esteve colada, principalmente, à política de sustentação financeira da estabilização monetária adotada e mantida desde 1994. A necessidade do governo federal de robustecer seu caixa para viabilizar a estratégia macroeconômica fez com que ele optasse por expandir a arrecadação das contribuições sociais na composição total da carga tributária, já que a receita desses tributos não é repassada a Estados e municípios. Dado, porém, que 
as contribuições sociais existem tendo por trás vinculações orçamentárias constitucionais específicas, foi preciso que o governo criasse formas de desvinculação de parte desses recursos, o que foi feito em diferentes momentos pelo Fundo Social de Emergência (FSE), Fundo de Estabilização Fiscal (FEF) e mais recentemente pela Desvinculação de Receitas da União (DRU), agora aumentada de $20 \%$ para $30 \%$ da arrecadação primária sobre a qual incide. Assim, olhando a questão apenas por esse ângulo, pode-se afirmar que a estratégia de financiamento federal dos anos 1990 e 2000 no Brasil logrou deslocar recursos potenciais do orçamento social para o ajuste macroeconômico, colocando teto à capacidade de gastos sociais em todo o período considerado.

Outro conjunto de constrangimentos às finanças sociais brasileiras está relacionado com a estrutura tributária regressiva do País. Nesse quesito, a discussão sobre a carga e sobre a estrutura tributária é totalmente estéril se desvinculada de pelo menos dois aspectos. Em primeiro lugar, o problema não está necessariamente em quanto o Estado arrecada da sociedade, mas fundamentalmente em como arrecada, ou seja, em quão progressiva ou regressiva é a estrutura de arrecadação imposta à sociedade. Em segundo lugar, vem a questão de como se gasta aquilo que se arrecada, isto é, em quão progressiva ou regressiva é a estrutura de gastos públicos estatais.

Com relação ao primeiro aspecto, a arrecadação pública está concentrada em tributos sobre o consumo de bens e serviços cuja incidência é proporcionalmente maior sobre parcelas da população que detêm os menores níveis de rendimentos. Tal regressividade se torna ainda mais problemática ao evidenciarmos o fato de que fazem parte desses tributos determinadas contribuições sociais destinadas ao custeio de programas sociais que são, assim, financiados indiretamente (por meio do consumo e da estrutura tributária regressiva) por seus próprios beneficiários.
Embora não se possa acusar a tributação sobre a folha salarial de regressiva, a situação na qual os contribuintes desses programas financiam seus próprios benefícios também se repete nesse caso. Por fim, a tributação sobre a renda e sobre o patrimônio, a despeito de serem bases de incidência detentoras de grande potencial quanto à progressividade, é pouco aproveitada no Brasil, haja vista sua pequena expressão na carga tributária total.

Do que foi dito, conclui-se que é pequeno o potencial de combate às desigualdades a partir da estrutura tributária nacional atualmente existente, já que o princípio do autofinanciamento da política social está nela enraizada. Uma forma de ver isso é lembrar que praticamente dois terços de todo o gasto social está vinculado a contribuições sociais feitas sobre a folha de salários. Ou seja, tendo em conta que o principal componente do Gasto Social Federal (GSF) é representado pelo gasto previdenciário, tem-se que, em sua maior parte, ele é financiado pelos próprios beneficiários, sendo o restante indireta e desproporcionalmente financiado pelas camadas mais pobres da população, por meio dos tributos que incidem sobre o consumo. Tomando por base, portanto, a regressividade da estrutura tributária, bem como o fato de a maior parte dos impostos e contribuições devidos por empregadores ser repassada aos preços, conclui-se que as classes que vivem do trabalho (e entre estas, as mais pobres) são as que, em verdade, financiam a maior parte dos gastos sociais no Brasil.

Com relação ao segundo aspecto, isto é, a forma pela qual se efetua a despesa pública, tem havido intenso e permanente deslocamento de recursos reais da área social para outras áreas do gasto federal, notadamente para a cobertura de despesas financeiras.

Assim, tudo o mais constante, a manter-se a função-objetivo primordial do atual governo, sob cuja batuta se deu o desalentador aniversário de 30 anos da CF-1988, 
no sentido de manter superavit primários elevados para garantir o refinanciamento da dívida pública, e transmitir a sensação de credibilidade e de governabilidade em prol da estabilização monetária, duas consequências imediatas se manifestam do ponto de vista da gestão social:

- As políticas sociais setoriais tornam-se insuficientes, diante do quadro de restrições macroeconômicas, para combater a estrutura profunda de desigualdades da sociedade brasileira;

- Os gastos sociais tradicionais tendem a se transformar (depois da infraestrutura social: saneamento e habitação) em fronteira politicamente possível do superavit primário. Tal parece ser, aliás, o objetivo de medidas tais como as contidas na EC $95 / 2017$, bem como daquelas destinadas à desvinculação do salário mínimo como indexador dos benefícios da previdência e da assistência social, e à desvinculação que as contribuições sociais e demais impostos possuem em relação aos principais componentes do gasto social federal.

É claro que restam ainda outras questões e problemas a enfrentar, estes também de dimensões consideráveis, a saber:

- Incremento de 'qualidade' dos bens e serviços públicos disponibilizados à sociedade;

- Equacionamento dos esquemas de 'financiamento' para diversas políticas públicas de orientação federal; e

- Aperfeiçoamentos institucionais-legais no espectro amplo do 'planejamento' governamental para a execução adequada (vale dizer: eficiente, eficaz e efetiva) e aderente (às realidades socioeconômicas) das diversas políticas públicas em ação pelo País.

Com relação à qualidade dos bens e serviços ofertados à sociedade, é patente e antiga a baixa qualidade geral destes e, a despeito do movimento relativamente rápido de ampliação da cobertura em vários casos (vejam-se, por exemplo, as áreas de saúde, educação, previdência e assistência social etc.), nada justifica o adiamento dessa agenda da melhoria da qualidade com vistas à legitimação política e à preservação social das conquistas obtidas até agora. A agenda da qualidade, por sua vez, guarda estreita relação com as duas outras mencionadas anteriormente: as dimensões do financiamento e do planejamento.

No caso do financiamento, é preciso enfrentar tanto a questão dos montantes a disponibilizar para determinadas políticas - ainda claramente insuficientes em vários casos - como a difícil questão da relação entre arrecadação tributária e gastos públicos. Há muitas evidências empíricas e muita justificação teórica acerca dos malefícios que estruturas tributárias altamente regressivas, como a brasileira, trazem para o resultado das políticas públicas e para a própria distribuição de renda e riqueza no País.

Em outras palavras, o impacto agregado destas, quando considerado em termos dos objetivos que pretendem alcançar, tem sido negativamente compensado, no Brasil, pelo perfil regressivo da arrecadação, que tem penalizado proporcionalmente mais os pobres que os ricos. Se essa situação não mudar, rumo a uma estrutura tributária mais progressiva, tanto em termos dos fluxos de renda como dos estoques de riquezas (físicas e financeiras) existentes no País, dificilmente haverá espaço adicional robusto para a redução das desigualdades econômicas, sociais e regionais, que clamam, há tempos, por soluções mais rápidas e eficazes.

Por fim, no caso da 'função planejamento governamental', trata-se não só de promover aperfeiçoamentos legais relativos aos diversos marcos institucionais que regulam a operacionalização cotidiana das políticas públicas, mas também de 
estimular e difundir novas técnicas, instrumentos e práticas de formulação, implementação e gestão de políticas e ações governamentais no espaço ainda discricionário que os gestores possuem.

Nesse particular, é preciso ter claro que a política social brasileira, comumente considerada, por analistas e setores conservadores da sociedade, como peso morto e elemento antagônico ao crescimento econômico, pode e deve, na verdade, dentro da perspectiva ética e analítica aqui adotada, ser vista como parte integrante de um projeto de desenvolvimento de longo prazo para o País, pois coloca a população - particularmente aquela vinculada ou circundada pelo salário mínimo - no centro dessa estratégia.

Para além dos princípios gerais acima sugeridos, há, evidentemente, uma agenda de reformas concretas inadiáveis, que aqui apenas se enunciam de modo não exaustivo, já que a concertação política necessária à sua viabilidade institucional e implementação no âmbito do Estado brasileiro depende obviamente da restauração democrática de fato e de direito no País. São elas:

- A 'reforma tributária e fiscal': progressiva na arrecadação e redistributiva nos gastos;
- A 'revolução técnico-científica-produtiva': ancorada nos fundamentos da economia verde, com ênfase em educação ambiental desde a primeira infância, produção e difusão de tecnologias limpas, promotora de encadeamentos inovativos de amplo alcance, ou seja: inovação produtiva e institucional de processos e produtos;

- A 'refundação dos poderes Legislativo e Judiciário': a reforma do sistema representativo e de partidos políticos, o fortalecimento dos instrumentos de democracia direta e dos mecanismos coletivos de participação e deliberação, a desconcentração econômica e democratização dos meios de comunicação e do sistema de justiça;

- A 'revolução na cultura dos direitos': institucionalização e substantivação dos direitos humanos, econômicos, sociais, culturais e ambientais.

É essa a aposta (e a utopia!) analítico-interpretativa sugerida por este balanço crítico acerca dos 30 anos da CF-1988, e é essa a aposta político-institucional de construção coletiva que os governantes brasileiros deveriam se impor neste século XXI. 


\section{Referências}

1. Bercovici G. Constituição Econômica e Desenvolvimento: uma leitura a partir da Constituição de 1988. São Paulo: Malheiros; 2005.

2. Cardoso Jr JC, organizador. A Constituição Brasileira Revisitada: recuperação histórica e desafios atuais das políticas públicas nas áreas econômica e social. Brasília, DF: IPEA; 2009.

3. Cardoso Jr JC, Castro PF, Mota D, organizadores. A Constituição Brasileira Revisitada: recuperação histórica e desafios atuais das políticas públicas nas áreas regional, urbana e ambiental. Brasília, DF: IPEA; 2009. $2 \mathrm{v}$.

4. Comparato FK. Muda Brasil: uma Constituição para o desenvolvimento democrático. São Paulo: Brasiliense; 1986.

5. Fiocca D, Grau ER, organizadores. Debate sobre a Constituição de 1988. São Paulo: Paz e Terra; 2001.

6. Fonseca F, Brelàz G, Gomes MV, organizaadores. A Constituição Federal de 1988: avanços e desafios. São Paulo: Hucitec; 2010.

7. Instituto de Pesquisa Econômica Aplicada. Políticas Sociais: acompanhamento e análise. Vinte Anos da Constituição Federal. Brasília, DF: IPEA; 2009.
8. Gomes ME, coordenadores. A Constituição de 1988, 25 Anos: a construção da democracia \& liberdade de expressão: o Brasil antes, durante e depois da constituinte. Rio de Janeiro: Instituto Vladimir Herzog; 2013.

9. Grau ER. A Ordem Econômica na Constituição de 1988:interpretação e crítica. São Paulo: Malheiros, 2008.

10. Lopes JAV. A Carta da Democracia: o processo constituinte da ordem pública de 1988. Rio de Janeiro: Topbooks, 2008.

11. Oliven RG, Ridenti M, Brandão G, organizadores. A Constituição de 1988 na Vida Brasileira. São Paulo: Aderaldo \& Rothschild; Anpocs, 2008.

12. Praça S, Diniz S, organizadores. Vinte Anos de Constituição. São Paulo: Paulus; 2008.

13. Ribeiro PH, Guerra AM, Bernardes WL, et al. 25 Anos da Constituição Brasileira de 1988: democracia e direitos fundamentais no Estado Democrático de Direito. São Paulo: D’Plácido; 2013.

Recebido em 24/07/ 2018

Aprovado em 24/08/2018

Conflito de interesses: inexistente

Suporte financeiro: não houve 